\title{
Seemings and Justification: An Introduction
}

\author{
Chris Tucker
}

\section{(Forthcoming in Seemings and Justification: New Essays on Dogmatism and Phenomenal Conservatism, OUP, edited by Chris Tucker)}

It is natural to think that many of our beliefs are rational because they are based on seemings, or on the way things seem. This is especially clear in the case of perception. You believe that there is a paper document (or a computer screen) in front of you because it seems visually that way. Many of our mathematical, moral, and memory beliefs also appear to be based on seemings. I believe that I ate cereal for breakfast because I seem to remember eating it for breakfast. And we believe that torturing for fun is morally wrong and that $2+2=4$ because those claims seem intuitively obvious. In each of these cases, it is natural to think that our beliefs are not only based on a seeming, but also that they are rationally based on these seemings - at least assuming there is no relevant counterevidence.

These initial reflections, however natural, raise three questions:

1) Is there really some state - a seeming - that is present in each case or is it just convenient to talk that way?

2) If these seemings really are genuine states or entities, what are they? Beliefs, experiences, or something else entirely?

3) What is the connection between seemings and justified belief: under what conditions, if any, can a seeming justify its content?

This volume focuses on the third question - the connection between seemings and justification - but the first two questions are obviously relevant to the third. If there is no such thing as a seeming, then there's likely no point in asking about the connection between seemings and justification. And whether it is plausible to hold that seemings can make their corresponding beliefs justified depends heavily on what seemings are. The contributors to Seemings and Justification (or S\&J) generally agree that seemings exist, except for Conee (S\&J, sec 2.1) who is officially neutral on the topic. On the other hand, they disagree widely over what seemings are and the circumstances, if any, under which seemings can justify their contents.

Phenomenal conservatism and dogmatism hold that there is a very tight connection between seemings and justification. Phenomenal conservatism (PC) holds that if it seems to $\mathrm{S}$ that $\mathrm{P}$, then, in the absence of defeaters, $\mathrm{S}$ thereby has justification for believing $\mathrm{P} .{ }^{1} \mathrm{As}$ I will use the term, dogmatism is essentially phenomenal conservatism restricted to some domain(s). (I define 'dogmatism' this way because it is captures the usage that, I think, is most prevalent in the minds of epistemologists; however, Pryor, who is largely responsible for the popularity of the term, uses it differently. ${ }^{2}$ ) Dogmatism about perception is the most popular version, and it holds that, if it perceptually seems to $\mathrm{S}$ that $\mathrm{P}$, then, in the absence

\footnotetext{
Notes

${ }^{1}$ Huemer $(2001,2006,2007)$ is most commonly associated with the view, but Cullison (2010, 272-74), Lycan (S\&J), Skene (forthcoming), and I (2010a, 2011) also endorse it.

${ }^{2}$ For Pryor, dogmatism about X holds that it's possible to have immediate but underminable justification for $\mathrm{X}$. On his usage of the term there is no presumption that the justification consists in the seeming, rather than say, the reliability of the associated process. That he does not intend the stronger, internalist reading is clearer in his later work (S\&J, sec 3; ms) than in his 2000.
} 
of defeaters, $\mathrm{S}$ thereby has justification to believe $\mathrm{P} .^{3}$ This volume explores the connection between seemings and justification by exploring the prospects of PC and various versions of dogmatism.

There are few topics in epistemology that have more wide-ranging implications than the one considered in this volume. The first paragraph is enough to suggest that the connection between seemings and justification is a crucial issue regarding perceptual, memorial, and a priori justification. ${ }^{4}$ The essays in this volume illustrate some of the broader importance of this connection by concerning (in no particular order):

- the content of perceptual experiences (Brogaard, Cullison);

- the epistemology of cognitive penetration (Brogaard, Markie, McGrath, this introduction);

- the epistemology of philosophical method (Brown);

- the epistemology of disagreement (DePaul);

- doxastic conservatism ${ }^{5}$ (Lycan, McGrath);

- testimonial justification (Audi);

- moral epistemology (Audi, Brogaard, Brown)

- the debate between internalism and externalism (Bergmann, Steup); and

- the correct formulation of Bayesian epistemology (Pryor, this introduction).

I preview the other entries to the volume in section 5. In the meantime, I provide a general introduction to dogmatism and phenomenal conservatism. In section 1, I consider the ontology of seemings and their relation to other mental states. In section 2, I survey the main motivations for dogmatism and phenomenal conservatism. In sections 3 and 4, I consider two main objections to dogmatism and phenomenal conservatism. The first concerns whether cognitive penetration poses a problem for those views. The second concerns the relationship between those views and classical Bayesian epistemology.

\section{Seemings: what are they?}

As we've already mentioned, it is natural to think that perceptual experiences, memorial experiences, and a priori intuitions are kinds of seemings or at least closely related to seemings. But what, exactly, are seemings?

\subsection{Accounts of seemings}

Here are three views. A seeming that $\mathrm{P}$ is:
Belief View
A belief that $P$.
Inclination View
An inclination, disposition, or attraction to believe that $\mathrm{P}$.
Experience View
An experience with the content $\mathrm{P}$ or a sui generis
propositional attitude that $\mathrm{P}$.

As these views are to be understood, one might accept the Belief View for some seemings and the Experience View for others. Or one might hold that there really are seemings but

\footnotetext{
${ }^{3}$ In addition to Pryor (2000), Audi (1993, 366), Chisholm (1989, 65), Chudnoff (2011); Pollock and Cruz (1999, 201); and Pollock and Ovid (2005) all endorse perceptual dogmatism.

${ }^{4}$ Most entries in the volume are relevant to perceptual justification. For discussion of memorial justification, see the entries of Audi and Brogaard. For discussion of a priori justification, see the entries by Brogaard, Brown, Lycan, and Markie.

${ }^{5}$ Doxastic conservatism, aka epistemic conservatism, is the claim that believing $\mathrm{P}$ provides prima facie justification for $\mathrm{P}$.
} 
allow more than one kind of state to count as a seeming: perhaps both a belief in and an inclination to believe Goldbach's conjecture count as a seeming that the conjecture is true.

The first of these three views is probably the least popular these days. Lycan endorses it in early work, provided that the beliefs in question are "spontaneous", or non-inferential (1988, 165-6). ${ }^{6}$ Swinburne $(2001,141-2)$ also endorses it, but he does so in an ecumenical spirit. He also allows that a seeming that $\mathrm{P}$ can be an inclination to believe that $\mathrm{P}$ (so he also endorses the Inclination View), and a belief that $\mathrm{P}$ has "quite a probability (but less than $1 / 2$ )" (142). The Belief View receives support from the idea that the verb "seems" is often used to report beliefs, especially beliefs that are not firmly held. When I say "It seems to me that the best economic policy is so and so", I might simply mean that I believe, perhaps tentatively, that the best economic policy is so and so.

Nonetheless, the Belief View is not widely endorsed these days, because it faces the Problem of Known Illusions. According to Huemer, we can tell that seemings, or appearances, "are different from beliefs from the fact that it may appear to one that $p$ while one does not believe that $p$ " $(2007,31)$. It might seem to me that the half-submerged stick is bent, even though I don't believe that it is. Indeed, it might seem to me that the stick is bent even though I know it isn't. ${ }^{8}$

Once it is appreciated that it can seem to one that $\mathrm{P}$ even though one doesn't believe $\mathrm{P}$, a natural move is to suggest that seemings are not beliefs, but inclinations to believe. When I disbelieve the stick is bent, it is at least plausible that many of us retain the inclination to believe that the stick is bent even when we resist that inclination. Consequently, the Inclination View has held a wider following than the Belief View and some version of it is endorsed by Ernest Sosa (1998, 258-9; 2007, ch. 3), Rogers and Matheson (2011), and as previously mentioned, Richard Swinburne (2001, 141-2). Another advantage of the Inclination View is that it makes seemings non-mysterious by reducing them to something that we apparently understand, namely inclinations to believe. ${ }^{9}$

Despite the advantages of the Inclination view, Huemer provides three arguments that seemings should not "be identified with dispositions or inclinations to form beliefs" (2007, 31, emphasis removed; cf. Cullison 2010). Argument 1: I can be so convinced that an appearance is illusory, that I'm not even inclined to believe it. It's at least possible that I'm so used to the bent-stick illusion that I'm not even inclined to believe that the stick is bent. Argument 2: seemings provide non-trivial explanations of what I'm inclined to believe, and they couldn't provide such explanations if they were identical to inclinations to believe. I'm inclined to believe that a computer is in front of me because it seems that way.

Argument 3: an individual can be inclined to believe things even though they don't seem true. I might be inclined to believe P because I really want it to be true, even though it doesn't seem true and perhaps seems false.

The Experience View has at least two different motivations. The first is that it avoids the problems faced by the Belief and Inclination Views. In other words, it can

\footnotetext{
${ }^{6}$ As I mention below, he now seems to hold the Experience View.

${ }^{7}$ If Williamson $(2007,3)$ holds that intuitions are intellectual seemings, then he likewise holds that a seeming that $\mathrm{P}$ can be a belief or an inclination to believe that $\mathrm{P}$. He could be construed as saying either that intellectual seemings are beliefs/inclinations or that there is no such thing as intellectual seemings (217). I don't know what his official view is.

${ }^{8}$ Lyons $(2009,71-2)$ rejects this argument by relying on a popular, functionalist account of belief.

${ }^{9}$ As Pryor has pointed out to me, many of Huemer's objections to the Belief and Inclination views are reminiscent of points made by Jackson (1977, sec 2) in his discussion of 'looks'.
} 
accommodate the following data: (i) it can seem to $\mathrm{S}$ that $\mathrm{P}$ even if $\mathrm{S}$ doesn't believe that $\mathrm{P}$; (ii) it can seem to $\mathrm{S}$ that $\mathrm{P}$ even if $\mathrm{S}$ isn't inclined to believe that $\mathrm{P}$; (iii) a seeming to $\mathrm{S}$ that $\mathrm{P}$ can explain why $\mathrm{S}$ is inclined to believe $\mathrm{P}$; and (iv) $\mathrm{S}$ can be inclined to believe that $\mathrm{P}$ even if it doesn't (and never did) seem to S that P.

The second motivation applies only to those who think at least some seemings can provide non-inferential justification for their contents. Suppose you hold that seemings can justify. You may wonder what seemings must be like in order to play that justifying role. If you reject doxastic conservatism (the claim that merely believing $\mathrm{P}$ can provide prima facie justification for its content ${ }^{10}$ ), you aren't going to think that beliefs can justify their own contents. So you will reject the Belief View (at least, you will reject the Belief View for those seemings that you think justify their contents). And if beliefs don't justify their contents, it's hard to see why inclinations to believe justify their contents. So you will likely reject the Inclination view of seemings. Since many philosophers allow experiences to provide non-inferential justification for their contents, it is natural to think of seemings as experiences. This second motivation may partly explain why the Experience View has been so popular among those sympathetic to dogmatism or phenomenal conservatism. Its proponents include George Bealer (2000), Eli Chudnoff (2011), Andrew Cullison (2010), Michael Huemer (2001, 2005, 2007), William Lycan (S\&J), Jim Pryor (2000), Matthew Skene (forthcoming), and yours truly (2010a, 2011).

Proponents of the Experience View generally agree about three things. First, seemings have propositional content. ${ }^{11}$ Second, they are distinct from any sort of belief or inclination. Third, seemings have their own distinctive phenomenal character (e.g., Pryor 2000, 547, n37; Huemer 2001: 77; and Tucker 2010a: 530). Whether proponents of this view say that seemings are sui generis propositional attitudes or experiences seems to depend more on terminological preference than substantive disagreement.

When seemings are characterized as experiences or sui generis propositional attitudes, many find seemings obscure or non-existent. A critic might think, "I understand what a belief is. I understand what an inclination to believe is. When I introspect, I can find beliefs and inclinations to believe. But I don't have a grip of some sui generis propositional attitude thing you call a 'seeming,' and I can't find it when introspect" (cf. Williamson 2007, 217). Characterizing seemings as experiences may help insofar as people generally have a grip of what experiences are. But the progress is limited. On this view, seemings aren't just any experience: they are a special kind of experience. Okay, but what kind? Well, the kind that has this really neat and distinctive phenomenal character. Okay, but what phenomenal character? It's at this point that proponents of the Experience View resort to ostension/examples (e.g., when you are looking at a tree, it seems to you that a tree is in front of you) and metaphor (a seeming that $\mathrm{P}$ "recommends" $\mathrm{P}$ as true or "assures" the subject of P's truth). ${ }^{12}$ If that's the best the proponent of the Experience View can do, one may well doubt that there is any such distinctive phenomenal character and

\footnotetext{
${ }^{10}$ Prima facie justification $=$ justification in the absence of defeaters (e.g., relevant counterevidence).

${ }^{11}$ There are, of course, many accounts of perceptual experience which hold that perceptual experiences lack propositional content. In the terminology I discuss in 1.2, I think those accounts are more naturally construed as accounts about sensations rather than seemings. In any event, those who most clearly endorse dogmatism or phenomenal conservatism tend to hold that seemings have propositional content, and so for space reasons, I'm ignoring accounts of dogmatism and phenomenal conservatism that might wish to get by without the claim that seemings have propositional content.

${ }^{12}$ See my 2010a: 530.
} 
may wonder whether there is any such thing as a seeming at all (cf. Tooley S\&J, especially secs. 2-4).

Seeming realists (those who think seemings exist) who are dissatisfied with the apparent obscurity of the Experience View have reason to look for an alternative account of seemings. At this point, it is worthwhile to reflect on the general argumentative strategy that Huemer launched against the Belief and Inclination Views. Huemer argued that seemings aren't beliefs by arguing that a seeming that $\mathrm{P}$ is not a belief that $P$. Likewise, Huemer argued that seemings aren't inclinations by arguing that a seeming that $\mathrm{P}$ is not an inclination to believe $P$. This raises the question of whether the Belief or Inclination Views can be resuscitated by reducing a seeming that $\mathrm{P}$ to a belief or inclination to believe a proposition other than $P$. A seeming that $\mathrm{P}$ might be:

Evidence-Taking View A belief or inclination to believe of some mental state $M$ that it counts in favor of $P$.

According to this view, if it seems to me that a police officer is in front of me, I'm inclined to take some mental state - maybe the sensation of the blue uniform - as evidence that there is a police officer in front of me. Conee $(S \& J)$ and Tooley $(S \& J)$ can be construed as proposing some version of the Evidence-Taking view, but such a construal oversimplifies Conee's views somewhat. For he wants to leave it open that there is no semantic or ontological unity behind our seeming talk.

The Evidence-Taking View has two potential advantages. First, it avoids the potential obscurity that afflicts the Experience View. Second, it arguably avoids all the problems that afflict the Belief and Inclination Views. For example, one problem with the Inclination View was that I might be so used to the illusion that I'm no longer even inclined to believe that the half-submerged stick is bent. The proponents of the Evidence-Taking View can accommodate this sort of case if you retain the inclination to treat the visual image of the stick as evidence that the stick is bent. (See Huemer S\&J, sec 1.6 for criticisms of the Evidence-Taking View.)

Despite its advantages, proponents of dogmatism and phenomenal conservatism have reason to resist this account. It's hard to see how taking something to be evidence for P, by itself, can justify P. Perhaps justifiably taking oneself to possess evidence for P can justify $\mathrm{P}$, but dogmatism and phenomenal conservatism do not require the seemings to be justified and typically deny that seemings admit of justification. It's no surprise, then, that the Evidence-Taking View was put forward by critics of dogmatism and phenomenal conservatism.

\subsection{Seemings and the ontology of the mind}

Recently, philosophers have been re-examining the relationship between seemings and other mental states. The most popular subject of re-examination is the relationship between seemings and sensations, or sensory experiences. Huemer (2001, 58-79) and Tolhurst $(1998,300)$ hold that sensations are a kind of seeming. On their view, we have seemings of many kinds - perceptual, memorial, and intellectual, perhaps among others - and the perceptual seemings are identical to sensations. Its seeming to you that the book is before you is identical to the visual image you have of the book's being before you. Brogaard (S\&J), Bergmann (S\&J, sec 1.3), Conee (S\&J), Sosa (2007, 48), and I (2010a, sec 1; 2011, $\sec 2.2)$ all reject this view and hold that sensations are a distinct state from perceptual 
seemings. ${ }^{13}$ Since Conee and Sosa deny that seemings are experiences, perhaps it is no surprise that they think there is a distinction between seemings and sensations. It is more surprising to see a proponent of the Experience View of seemings, like me, defend this assumption. To grasp the distinction between seemings and sensations, consider the following example of facial recognition.

Suppose you and I are looking at the face of some person who, unbeknownst to you, happens to be my wife. We would have a mental "picture" of her in our minds. This "picture" might look and feel exactly the same to us, i.e. our mental images of my wife would be phenomenally identical. These phenomenally identical images are (visual) sensations. Although there is no phenomenal difference with respect to our sensations, there is a phenomenal difference in the way things seem. It would seem utterly obvious to me that she is my wife. On the other hand, it would not seem to you that she is my wife, and if anything, it would seem utterly obvious to you that you have no idea who you are looking at. Despite having phenomenally identical sensations, we have different seemings. A plausible explanation is that seemings are not identical to sensations.

A proponent of the seeming/sensation distinction will likely hold that typical cases of perception involve both a seeming and a sensation. Visual perception will involve a seeming and a "visual image". Auditory perception will involve a seeming and a "mental sound," and so on for at least gustation and olfaction. A proponent of this distinction is also likely to find a parallel distinction in other domains. I seem to remember eating cereal for breakfast. This memorial seeming accompanies but is distinct from something like a degraded visual image of my cereal bowl (cf. Plantinga 1993, 58). My seeming that some act of torture is wrong may be accompanied by my revulsion of the act in question. In each of these cases, the dogmatist may say that while only the seeming has justificatory power, sensations, memorial imagery, and moral emotions play a crucial role in belief formation, perhaps by causing it to seem a certain way. ${ }^{14}$

The distinction between seemings and sensations has important implications for both epistemology and the philosophy of mind. In epistemology, for example, it is alleged that this distinction plays an important role in resolving the speckled hen problem (Tucker 2010a, sec 3; Brogaard S\&J, sec 5). In philosophy of mind, for example, the distinction is claimed to undercut important arguments for the claim that sensations represent not only shape and color, but also more complex properties, such as being a pine tree, being a policeman, and being an instance of causation (cf. Brogaard S\&J). ${ }^{15}$

\section{Motivations for dogmatism and phenomenal conservatism}

If you listen to the proponents of dogmatism and phenomenal conservatism, the advantages of those views are legion. First, dogmatism is thought to be the natural view for perception,

\footnotetext{
${ }^{13}$ Plantinga (1993, 91-2) may be taken as giving, at the very least, a precursor to the seeming/sensation distinction. Lyons' (2009, ch 3 ) distinction between sensations and percepts also bears some connection with the seeming/sensation distinction. Chudnoff (2011) does think there are some important distinctions to be made between those experiences that have what he calls 'presentational phenomenology', such as seemings, and those that don't. But his distinction seems very different than the one being considered here.

${ }^{14}$ Cf. Brogaard (S\&J, sec 3).

${ }^{15}$ For other examples of this distinction's importance within epistemology, see Tucker (2010a; 2011, secs

2.2-3) and Brogaard (S\&J, sec 5). For other examples in the philosophy of mind, see Cullison (S\&J).
} 
intuition, memory, or some combination thereof. ${ }^{16}$ Second, dogmatism avoids both scepticism and regresses of justification. Third, dogmatism has been claimed to provide straightforward resolutions to certain epistemological issues, such as the speckled hen problem, expert recognition, and certain obstacles for coherentist explanationism. ${ }^{17}$

A fourth potential advantage is that a view like phenomenal conservatism provides a single principle that unifies all non-inferential justification, including perceptual, introspective, memorial, and a priori, and perhaps also inferential justification. ${ }^{18}$ Sober reflection, however, does raise some worries about this alleged advantage. It is natural to think that, at any given time, the vast majority of our beliefs are stored in long term memory and are not presently in our consciousness. Yet, if seemings are the sort of things that are necessarily occurent, presumably a belief's content will seem true only if it is in consciousness. How, then, can seemings explain the justification of beliefs that are not presently in consciousness? ${ }^{19}$

I think it is largely acknowledged that dogmatism and phenomenal conservatism have at least some of the above virtues, especially the first two; but detractors tend to think that there are disadvantages which more than outweigh these advantages. ${ }^{20}$ There are two additional arguments for phenomenal conservatism which are more controversial. The first is Michael Huemer's (2007) self-defeat argument, which tries to show that you cannot justifiably believe that phenomenal conservatism is false. Skene (forthcoming, sec 3) defends the argument, but otherwise the argument has been widely criticized for a variety of reasons. ${ }^{21}$ Even some proponents of phenomenal conservatism wish to distance themselves from the self-defeat argument. ${ }^{22}$ Regardless of whether the self-defeat argument for phenomenal conservatism fails, a more limited self-defeat argument for dogmatism about intuitions may nonetheless be viable. ${ }^{23}$

Another motivation for phenomenal conservatism is its ability to capture certain internalist intuitions. It's no secret that internalists tend to think that there is some very tight connection between justification and one's first person perspective. The driving thought behind many internalisms is something like this: given my current situation, what should I believe now? And if something like that approach appeals to you, phenomenal conservatism may be appealing also. McGrath (S\&J, sec 1) puts the point this way:

\footnotetext{
${ }^{16}$ Pryor $(2000,538)$ holds that it is the natural view of perception. Chudnoff $(2011,315)$ agrees and adds that it is also the natural view with regard to intuition (322). Brown (S\&J) argues that it is natural to hold that intuition provides immediate justification, but she does not commit herself to dogmatism or the claim that intuitions are seemings. Pollock and Cruz $(1999,48)$ hold that it is the natural view of memory.

${ }^{17}$ For resolutions to the first two issues, see Brogaard S\&J (sec 5) and my 2010a (secs 3, 5). For a resolution to the third issue, see Lycan S\&J.

${ }^{18}$ Huemer (S\&J) holds that even inferential justification can be reduced to the way things seem. I disagree and hold only that seemings have a role to play in inferential justification (see my 2012).

${ }^{19}$ Audi (S\&J, sec 2) also has doubts that seemings can account for all testimonial justification.

${ }^{20}$ For example, although White $(2006,527-28)$ rejects dogmatism, he apparently grants it has at least the first two advantages. Markie (S\&J) apparently grants that perceptual dogmatism has the first three advantages (see especially sec 2 ).

${ }^{21}$ These criticisms include Conee S\&J; DePaul 2009; DePoe 2011; Hasan forthcoming; Markie S\&J; and Tooley S\&J. For some replies, see Huemer's 2009, 2011a, and his entry in S\&J.

${ }^{22}$ I hereby distance myself from the argument, and Lycan (S\&J, nt 11) does too.

${ }^{23}$ Bealer (1992) defends the more limited self-defeat argument. Audi (S\&J, sec 5.1) and especially Lycan (S\&J, sec 4) note sympathy with the more restricted self-defeat argument.
} 
Suppose it seems to you that $\mathrm{P}$ and you have no defeaters (i.e., no good evidence for not-P and no good evidence that this seeming is unreliable as to whether $\mathrm{P}$ ). Which doxastic attitude would it be reasonable for you to have toward P?

Disbelieve P, without good evidence for not-P? [That doesn't seem reasonable.] Withhold judgment on P? It does seem to you that P, and you lack evidence for not$\mathrm{P}$ and for the unreliability of the seeming with respect to P. [So it doesn't seem reasonable to withhold judgment either.] The only reasonable attitude to take is belief. $^{24}$

The plausibility of McGrath's reasoning suggests that epistemologists need to account for: McGrath's Datum when it seems to you that $\mathrm{P}$ in the absence of defeaters, you bear a relation to $\mathrm{P}$ which makes it irrational to disbelieve or withhold judgment about $\mathrm{P}$.

Huemer (2006) gives the most detailed and sustained defense of this motivation. His basic idea is this. If you fix the way things seem, you fix what is epistemically relevant from the subject's perspective. Suppose a theory allows something besides a seeming to contribute to what one ought to believe. Huemer holds that such a theory would be committed to this odd result: there could be some propositions $\mathrm{P}$ and $\mathrm{Q}$ such that a subject ought to affirm $\mathrm{P}$ and deny or withhold $\mathrm{Q}$ while at the same time acknowledging that, insofar as he can tell, $P$ and $Q$ are exactly alike in all epistemically relevant respects (cf. 2006: 151). The plausibility of Huemer's reasoning suggests that epistemologists need to account for:

Huemer's Datum when P and Q seem alike in all epistemically relevant respects, it is irrational to treat the two propositions differently (e.g., believe one but disbelieve the other).

The phenomenal conservative can provide straightforward explanations of these two data. Since an undefeated seeming that $\mathrm{P}$ would justify $\mathrm{P}$, it would be irrational to disbelieve or withhold judgment about P. Thus, McGrath's Datum is explained. Since there is no relevant difference in the way that $\mathrm{P}$ and $\mathrm{Q}$ seem, the two propositions shouldn't be treated differently. Thus, Huemer's Datum is also explained. Do these data give us reason, by themselves, to endorse phenomenal conservatism? Not obviously, for there is another explanation that Huemer and McGrath fail to rule out. ${ }^{25}$

To understand this alternative, we need to introduce rational commitment. $\mathrm{S}$ is rationally committed to taking some attitude $\mathrm{A}$ toward $\mathrm{P}$ just in case, if one takes an attitude toward P, it is irrational not to take A toward P (cf. Pryor 2004: 363-4, forthcoming, sec V). Suppose I believe P. I am rationally committed to believing $P$ or $Q$. Perhaps it is perfectly sensible to ignore $P$ or $Q$, to take no attitude toward that disjunction at all; however, if I do take an attitude toward that disjunction, as long as I continue to believe $\mathrm{P}$, I would be irrational if I disbelieved or withheld judgment about $P$ or $Q$. The problem is that such a combination of attitudes would be incoherent.

In the above example, I am rationally committed to believing $P$ or $Q$. Yet it does not follow that I am justified in believing $P$ or $Q$. If I believe $P$ or $Q$ solely on the basis of my belief in $\mathrm{P}$, my belief in $P$ or $Q$ is justified only if my belief in $\mathrm{P}$ is justified. If my beliefs

\footnotetext{
${ }^{24}$ Although McGrath clearly has some sympathy with this line of reasoning, it is unclear to what extent he ultimately endorses it. Cf. Huemer 2001, 104-5.

${ }^{25}$ I owe the following objection to Jackson 2011, but the presentation of the objection is my own. McGrath $(\mathrm{S} \& \mathrm{~J})$ provides an alternative way to press the objection.
} 
do not violate my rational commitments, they will avoid a certain kind of incoherence. Yet justification requires more than simply avoiding this incoherence.

The alternative explanation of the two data is provided by (phenomenal) semiconservatism: Necessarily, if it seems to $\mathrm{S}$ that $\mathrm{P}$, then, in the absence of defeaters, $\mathrm{S}$ is thereby rationally committed to believing $\mathrm{P}^{26}$ If semi-conservatism is true but phenomenal conservatism is false, then a seeming might make it irrational to not believe $\mathrm{P}$ (assuming I take an attitude toward $\mathrm{P}$ at all) without making me rational, or justified, in believing P. In such a case, I'm at an epistemic dead end, a situation in which there is no rational, or justified, attitude that one can take toward $P$.

Consider an analogy. Suppose I take it as my ultimate end to eat every rock I find. I find a rock. Eating that rock is a necessary means to my ultimate end, so I'm rationally committed to eating the rock; it would be irrational for me to ignore the rock and carry on with my day. Yet my end of eating rocks is downright stupid and stupid ends can't make it rational to take the necessary means to those ends. So I'm at a practical dead end: (as long as my ultimate aim remains the same) I'm irrational whether I eat the rock or not.

Back to epistemology. Suppose that a seeming can't even prima facie justify a proposition when it has a bad causal history, even if the subject is now completely unaware of the bad causal history (and so even if the causal history doesn't provide a defeater). Perhaps the seeming is a memorial seeming that $\mathrm{P}$ which is the product of forgotten irrationality. Given semi-conservatism, this seeming that $\mathrm{P}$ rationally commits one to believing $\mathrm{P}$, and so makes it irrational to disbelieve and withhold judgment about P. Yet, on the assumption that bad causal histories nullify (prima facie) justificatory power, one would also be irrational for believing P. So one is at an epistemic dead end: (as long as the causal history of one's seeming remains the same) one is irrational no matter what attitude one takes toward P.

The semi-conservative explanation of the two data should now be relatively clear. Since a seeming that $\mathrm{P}$ rationally commits one to $\mathrm{P}$, it would be irrational to disbelieve or withhold judgment about P. McGrath's Datum is thereby explained. If epistemic dead ends are possible, it may nonetheless be irrational to believe $\mathrm{P}$ and $\mathrm{PC}$ would be false. By adding a few details, we get a plausible explanation of Huemer's Datum. The subject may compare the memorial seeming that $\mathrm{P}$, which has a bad causal history, with a memorial seeming that $\mathrm{Q}$, which has a good causal history. It might seem to the subject that $\mathrm{P}$ and $\mathrm{Q}$ are alike in all epistemically relevant respects (again, the subject isn't aware of the bad causal history of her seeming that $\mathrm{P}$ ). In such a case, semi-conservatism can say it would be irrational for the subject to treat P and Q differently (e.g., believe one and withhold judgment about the other). Huemer's Datum is thereby explained. If epistemic dead ends are possible, S nonetheless might be justified in believing only Q and so PC would false. Until the phenomenal conservative shows that epistemic dead ends are impossible or finds some other reason to prefer the phenomenal conservative explanation over the semiconservative one, internalist intuitions don't, by themselves, support phenomenal conservatism. $^{27}$

\footnotetext{
${ }^{26}$ They don't address this question, but Markie, McGrath, and Brogaard may each endorse phenomenal semiconservatism (or semi-dogmatism, if you prefer) despite their rejection of phenomenal conservatism.

${ }^{27} \mathrm{McGrath}$ (S\&J, sec 2) suggests that the best explanation of a seeming's ability to rationally commit may be its ability to justify. If so, it would not be viable to endorse semi-conservatism while rejecting phenomenal conservatism. McGrath, however, only mentions this suggestion and doesn't defend it. In addition, I don't
} 


\section{Cognitive penetration objections}

Dogmatism and phenomenal conservatism allow seemings to justify their contents no matter how they are caused. A natural way of attacking these views is to consider seemings whose causal histories appear incompatible with the seemings' providing even prima facie justification. The most common ways of pushing this objection appeal to cognitively penetrated seemings. For our purposes, we can say that $\mathrm{S}$ 's seeming that $\mathrm{P}$ is cognitively penetrated by S's mental state M just in case M (partly) causes that seeming that P. If my desires, beliefs, experiences, or other seemings (partly) cause me to have a seeming that $\mathrm{P}$, then that seeming that $\mathrm{P}$ is cognitively penetrated.

It's worth stressing that cognitive penetration, by itself, is not a bad thing. Consider the lizard-like tuatara. As a symbol of its premier status in the animal kingdom, there is a New Zealand brewing company named after it. As should be obvious to anyone, if alcoholic beverages aren't named after you, you're not that important. But I digress. More to the point: I look at the tuatara and it seems to be some kind of lizard; but it isn't. The background beliefs of an expert might make it seem to the expert that the creature is a tuatara, not a lizard. The expert's cognitively penetrated seeming doesn't seem problematic, and if anything, seems to enhance the expert's cognition. When a seeming is cognitively penetrated by relevant and justified beliefs, there often doesn't seem to be any problem with basing your belief on the relevant seeming. ${ }^{28}$

\subsection{Cognitive penetration by justifiers}

Although not all cognitive penetration is bad, some might be. One way of pushing cognitive penetration worries can be called the Illegitimate Boost Objection. The basic idea is that when your seeming that $\mathrm{P}$ is causally dependent on, so cognitively penetrated by, a legitimate justification for $\mathrm{P}$, it is implausible to suppose that the seeming does any extra justificatory work. ${ }^{29}$

Suppose you have some bit of evidence that doesn't depend on its seeming to you that $\mathrm{P}$. For example, suppose you accept $\mathrm{P}$ on the basis of a good argument. While you are thinking about how clever you are for coming up with that argument, $\mathrm{P}$ begins to seem true to you. Now you have two justifications for $\mathrm{P}$, the argument for $\mathrm{P}$ and its seeming that $\mathrm{P}$. So far, so good. But now suppose that your acceptance of the argument is what makes $\mathrm{P}$ seem true to you and that you are oblivious to this fact. Objectors claim that, according to phenomenal conservatism, the seeming that $\mathrm{P}$ would provide your justification a boost; however, this boost is claimed to be illegitimate because the seeming is completely dependent on the argument for P. I've heard this objection in conversation on multiple occasions. In print, I've seen the objection from Tooley (S\&J, sec 5.2.1) and, oddly enough, Huemer $(1999,348) .^{30}$

To see the problem with this objection, consider an analogy with testimony. Suppose that Bill testifies $(\mathrm{P})$ that there is free pizza on the quad. You aren't convinced, but his

know to what extent that he himself endorses this suggestion. He clearly rejects phenomenal conservatism, but what he says in the paper seems compatible with semi-conservatism.

${ }^{28}$ See Lyons' (2011, sec 2) for further examples of benign cognitive penetration.

${ }^{29}$ In such a case, the objector might say, you would double count the justificatory force of the original legitimate justification: you would count its force once directly and once indirectly via the seeming. Hence, in S\&J, Tooley and Huemer refer to this objection as the Double Counting Objection.

${ }^{30}$ Audi (S\&J, sec 2.2) discusses a related worry. 
testimony does give you some reason to believe that $\mathrm{P}$. Then Jill comes along and also testifies that P. You have no special reason to believe that her testimony is dependent on Bill's. It seems reasonable to raise your confidence in $\mathrm{P}$; her testimony gives your justification in $\mathrm{P}$ a boost. And this is so, even if, unbeknownst to you, Jill believes that $\mathrm{P}$ only because Bill told her. Once you learn that her testimony is dependent on Bill's, her testimony no longer provides you with a boost. Likewise, when you don't know that your seeming causally depends on another justification, it can provide a boost. When you learn that the seeming causally depends on another justification, it can't provide a boost.

We might quibble over the details of the example, but the key point is this. A second justification, whether dependent or not, whether in the form of seemings or testimony, can provide a legitimate boost to your justification when you reasonably believe the two justifications to be completely independent. They can't add boosts when you reasonably believe them to be completely dependent (cf. Huemer S\&J, sec 3.3). What's less clear is what to say about the intermediate cases, such as when you have no evidence one way or another concerning the independence of justifications. These cases are challenging, but they are no more challenging for the dogmatist than they are for anyone else.

\subsection{Cognitive penetration by non-justifiers}

The Illegitimate Boost Objection appealed to seemings that are cognitively penetrated by mental states that constitute legitimate justification for the target proposition. The Tainted Source Objection, ${ }^{31}$ perhaps the most common objection to dogmatism, appeals to seemings that are penetrated by mental states that are not legitimate justifications for the target proposition, such as desires and unjustified beliefs.

Consider a case of cognitive penetration by desire. Suppose it seems to Wishful Willy that the yellow object is gold, because he wants it to be gold. Most epistemologists find it counterintuitive to allow his wishfully produced seeming to provide him with prima facie justification that the nugget is gold. ${ }^{32}$ Or suppose that Jill irrationally believes that Jack is angry. Jack walks into the room, and her irrational belief makes it seems to her that Jack is angry. Most epistemologists find it counterintuitive to allow Jill's seeming to provide her with justification that Jack is angry. ${ }^{33}$

Those who press this sort of objection against dogmatism often attempt to diagnose precisely what's wrong with the problematic sort of cognitive penetration. Siegel (2011) speculates that the problem is a kind of circularity. Lyons (2011) suggests the problem is a lack of reliability. McGrath (S\&J, secs. 4, 5) suggests that the problem boils down to free enrichment. Roughly, a seeming that $\mathrm{Q}$ is freely enriched when it is cognitively penetrated by a seeming that $\mathrm{P}$ and $\mathrm{P}$ does not support $\mathrm{Q}$. I leave examination of these diagnoses for another occasion.

Although I'm a proponent of phenomenal conservatism, I have the intuitions that the objectors want me to have in some of the cases at least some of the time. But not everyone shares the intuitions of the objectors. Lycan (S\&J, sec 7) and Huemer (S\&J, sec 5) apparently don't have the intuition that, say, wishfully-produced seemings can't provide

\footnotetext{
${ }^{31}$ I get this name from Huemer (S\&J).

${ }^{32}$ See, e.g., Goldman (2009, 330), Lyons (2011), Markie (2005: 356-7; S\&J), Siegel (2011), and Steup (S\&J, $\sec 6)$.

${ }^{33}$ This example is Siegel's (2011). Forgotten irrationality objections to dogmatism about memorial justification have a similar structure. See, e.g., Goldman (2009: 323).
} 
prima facie justification for their contents. If the subject in such cases fails to have ultima facie justification, it is because they have a defeater (e.g. they have good reason to believe they are unreliable on the topic). Still, the intuitions are widely shared, and it would be a significant coup for dogmatists if they could account for these intuitions without giving up their dogmatism. In what follows, I will focus on the simple Wishful Willy case, because that's the case that I find most counterintuitive and the case that, to me, incorporates the fewest distracting details. ${ }^{34}$

A popular line of response is to concede that our intuitions are picking up on a legitimate defect but then deny that the defect is that the cognitively-penetrated seeming can't provide prima facie justification. In other words, this approach distinguishes between prima facie justification and some other status and then says that our negative reaction to the wishfully-produced seeming is due to the failure to attain this other status. So what is this other status (or lack thereof) that our intuitions allegedly track?

Depending on the case in question, I've made two different suggestions (2010a, sec 6; cf. 2011, sec 5). I argue that a wishfully-produced seeming can provide prima facie justification even though it can't provide warrant for its content, where warrant is the property that makes true belief knowledge. This result would be parallel to a common view of new evil demon cases: the experiences of demon victims provide prima facie justification for their contents, but demon-caused seemings can't provide warrant for their contents. I also distinguish between justification and epistemic blameworthiness and argue that a subject would be epistemically blameworthy for having the wishfully-produced seeming, even though the seeming is still capable of providing prima facie justification for its content (cf. Huemer S\&J, sec 5). Markie (S\&J, sec 3) and McGrath (S\&J, sec 4) argue that these two suggestions cannot cover all the problematic cases. At the very least, these criticisms show that more needs to be said about blameworthiness for it to be clear that it is present in all the troublesome cognitive penetration cases.

Another suggestion is put forward by Skene (forthcoming, sec 5.1). He distinguishes between the evaluative properties of the agent and the evaluative properties of a belief based on the wishfully-produced seeming. His suggestion is that our intuitions are explained by our rightly criticizing the agent for having wishfully-produced seemings, but wishfully-produced seemings nonetheless provide prima facie justification. In other words, our intuitions correctly identify a defect in the subject's cognitive character, but this defect in character needn't entail a defect in the resultant cognitive "action", namely believing the content of the wishfully produced seeming. This response has initial appeal, but it faces a similar problem as my blameworthiness approach: without a more worked out theory concerning the appropriate conditions for criticizing agent and actions, it's not clear that this move will cover all problematic cases. ${ }^{35}$

\section{A Bayesian Objection to Dogmatism}

\footnotetext{
${ }^{34}$ Lyons (2011) also seems to think that cognitive penetration by desire provides the most forceful variant of the cognitive penetration objections.

${ }^{35}$ An alternative way of defending dogmatism against this objection is to show that, if dogmatism has a problem with cognitive penetration, then so do most other views in epistemology (see my manuscript). While this response doesn't show that dogmatism doesn't have a problem, if correct, it would prevent others from using dogmatism's alleged cognitive penetration problems as a reason to prefer their own view.
} 
We will focus on one Bayesian objection to dogmatism, though there are others. This objection consists of two stages: a formal proof and some interpretation of that proof. Since Pryor (S\&J, sec 6) discusses the proof at length, in 4.1, I will merely explicate the result of the proof and then present the standard interpretation of that result. In the following sub-sections, I consider three broad strategies for responding to this objection.

\subsection{Summary of the Objection}

The acquisition of new evidence $\mathrm{E}$ raises the probability of some propositions and lowers the probability of others. In such a case, we say that there has been an update on E. Let "Old" represent the probability of a proposition before the update on E and "New" be the probability of a proposition after. The relevant Bayesian objection focuses on a case in which $E$, the proposition we update on, is 'it seems to me that I have a hand'. $H$ is assumed to be 'I have a hand' and BIV the conjunction that 'I'm a handless brain-in-a-vat and I seem to have a hand.' For the sake of the objection, $\mathrm{E}$ is assumed to be evidence for $\mathrm{H}$. The proof establishes this:

$$
\text { Formal Result } \quad \operatorname{New}(\mathrm{H})<\mathrm{Old}(\sim \mathrm{BIV}) \text {. }
$$

In other words, the proof establishes that the probability that I have a hand will always be less than the antecedent probability of $\sim$ BIV. The antecedent probability of $\sim$ BIV sets an upper limit on how high $\mathrm{E}$ can raise the probability of $\mathrm{H}$.

The standard interpretation assumes that a proposition's having a certain degree of probability is its having a certain degree of justification. E's raising H's probability corresponds to E's justifying H. Since Old is the probability of a proposition before the update on E, it's natural to interpret Old as one's justification for a proposition antecedent to E's justifying $\mathrm{H}$. Acquiring E as evidence is understood as S's coming to know E. With this interpretation in place, the formal result becomes the:

Interpreted Result S's knowledge that E justifies $\mathrm{H}$ to some degree only if $\mathrm{S}$ has some higher degree of antecedent justification for $\sim$ BIV.

In other words, the antecedent justification of $\sim$ BIV places an upper limit on the justification that knowing $\mathrm{E}$ provides for $\mathrm{H}$.

Note that the formal result constrains, most directly, the degree of justification provided by knowing that it seems to me that I have a hand; however, dogmatism holds only that the having of the seeming confers prima facie justification. For this objection to even be relevant to dogmatism, the Bayesian objector relies on the proxy assumption: by focusing our attention on reflective subjects who know how things seem to them, we can understand the epistemic effects of seemings for all subjects. For the sake of the discussion, we shall simply grant this assumption. ${ }^{36}$ Once we do, the dogmatist is in an odd position. He tells us that seemings provide foundational, immediate justification, but Formal Result says that the immediate justification produced by seemings requires antecedent justification for rejecting sceptical hypotheses. But, while this is an odd position to be in, is it a problematic one? As we'll see, that's unclear.

\subsection{Strategy 1: Distinguish Necessary and Constitutive Conditions}

At this point, we need a sharper definition of dogmatism. I said that dogmatism about some domain is the claim that, within that domain, if it seems to $\mathrm{S}$ that $\mathrm{P}$, then, in the absence of

\footnotetext{
${ }^{36}$ For discussion of this assumption, see White (2006: 534-5) and Pryor (S\&J, sec 6). In note 41, I also point out that this assumption is problematic given agent-centered conceptions of justification.
} 
defeaters, S thereby has justification for P. I didn't explain what was intended by 'thereby'. The basic idea is that, in the absence of defeaters, the seeming justifies $\mathrm{P}$ all by itself. This means, in part, that one's seeming-based justification for $\mathrm{P}$ does not consist in justification for the denial of sceptical hypotheses. If the dogmatist can sensibly maintain that this antecedent justification for $\sim \mathrm{BIV}$ is a necessary condition on one's seeming-based justification for $\mathrm{H}$ (which is what Interpreted Result claims) while resisting the further claim that one's seeming-based justification partially consists in this antecedent justification, it's hard to see how the Formal or Interpreted Result pose any problem for dogmatism. Silins (2008, especially sec 4.1) was perhaps the first to make this sort of point, but he doesn't try to explain how dogmatism could be true if seeming-based justification requires antecedent, anti-skeptical justification. Without some explanation of this surprising result, Silin's position may seem like flat-footed stubbornness. That's where Wedgwood (forthcoming) comes in. ${ }^{37}$

The Bayesian objector typically assumes that one's antecedent justification must partially explain why it's rational for one to believe P when it seems that P. Wedgwood claims the typical objector gets things backwards: it's the fact that seemings make their corresponding beliefs rational that explains why we have antecedent justification for the denial of sceptical hypotheses (cf. Pryor S\&J, secs. 6-7). If dogmatism is true, then any thinker with the relevant concepts and abilities has at least one course of reasoning available to her that relies on dogmatism's truth and concludes that we have antecedent justification for the denial of sceptical hypotheses. One example involves re-understanding the nature and purpose of the much-maligned bootstrapping reasoning.

\subsection{Strategy 2: Distinguish Risk and Uncertainty}

Suppose you are considering $\mathrm{P}$ and have no evidence bearing on $\mathrm{P}$ at all. It's not that you have evidence for $\mathrm{P}$ and evidence for $\sim \mathrm{P}$ that balance each other out. It's not that you have evidence that the objective probability of $\mathrm{P}$ is .5. It's that your evidence is completely irrelevant as to whether P. In such a case, what credence, or degree of belief, are you justified in having? This is a notoriously difficult question. Whatever the answer is, let's say that such a credence would be based on ignorance. To the extent that ignorance justifies a certain credence in $\mathrm{P}$, the credence is said to be uncertain. To the extent that your evidence justifies a credence in $P$ that is less than 1 (say, because of less than conclusive evidence or knowledge of the objective chances), the credence is said to be risky.

Those sympathetic to dogmatism tend to think that there is an important difference between the epistemic effects of uncertainty and risk. For example, a dogmatist might argue that justification to have a low credence in the proposition I'm not being deceived has far more devastating consequences when it is risky than uncertain, when it is based on evidence than ignorance. Kung's (2010) attempt to exploit the distinction between risk and uncertainty is especially modest, because, like the approach in the previous sub-section, it can assume the classical Bayesian formalism for the sake of argument. His goal is to explain how, from within the classical Bayesian framework, one might try to model the difference between risk and uncertainty in a way that a dogmatist will find appealing. Pryor (ms), Weatherson (2007), and Weatherson and Jehle (ms), also think the Bayesian

\footnotetext{
${ }^{37}$ Wedgwood (forthcoming, sec $4 \mathrm{~b}$ ) rejects what he calls 'dogmatism', but he's using the term differently. He's a dogmatist, as I use the term.
} 
objection ignores important differences between risk and uncertainty, but they apparently think that to model these differences, we must reject the classical Bayesian's formalism.

\subsection{Replace the Formalism}

The third approach is to replace the classical Bayesian apparatus with a formal structure more friendly to dogmatism. The target is typically the classical Bayesian's update rule, which says roughly this: when you get evidence $\mathrm{E}$ for $\mathrm{H}, \mathrm{E}$ becomes certain and $\operatorname{New}(\mathrm{H})$ should always equal $\operatorname{Old}(\mathrm{H} \mid \mathrm{E})$. There is reason to be suspicious of this rule in this context. Weisberg (2009; and especially ms, secs. 1-2) has argued that this rule can't model pure undermining defeat. ${ }^{38}$ Now, the Bayesian objector doesn't rely on a pure undermining defeater. If you have evidence that you are a handless brain-in-a-vat that is being deceived into thinking you have a hand, you have evidence that rebuts and undermines: it both provides evidence against your having a hand and it provides evidence that your evidence that you have a hand is misleading or untrustworthy. Although Weisberg doesn't show that the classical Bayesian can't model a mixed defeater of this sort, his argument should make us wonder whether the fundamental problem is with, not dogmatism, but the classical approach to modelling undermining defeat.

Putting the previous sub-section together with this one, we see that the dogmatist has reason to find a formal apparatus that will be able to model two phenomena: pure undermining defeat and the epistemic differences between risk and uncertainty. Pryor (ms) and Weatherson (2007) take steps in that direction. Given how widely embraced these two phenomena are independently of dogmatism, constructing such a formal model is wellmotivated, even if it would overturn the classical update rule.

Jehle and Weatherson (ms) challenge a different component of Bayesian orthodoxy. Classical Bayesian holds, as a matter of logic, that $\operatorname{Pr}(\mathrm{P})+\operatorname{Pr}(\sim \mathrm{P})=1$. Their intuitionistic Bayesianism, on the other hand, denies that this claim is true as a matter of logic. If their intuitionistic alternative is assumed, they argue that the Formal Result does not hold. The alternative is a bit exotic, but let me ask you: are you certain that it is false? I'm not, and Weatherson and Jehle argue that the slightest bit of uncertainty is enough to save dogmatism.

At this point, it is not clear how the dogmatist should respond to objections that rely on the classical Bayesian formalism. But nor is it clear that the Bayesian objections reveal that dogmatists really have a problem. Indeed, if anybody has a problem here, it may be the classical Bayesians.

\section{What's in the Volume}

I now turn to introducing each entry in the volume. This section is divided into five subsections, one for each part of this book.

\subsection{Seemings and Seeming Reports}

The two essays in Part I aim primarily at clarifying seemings. Other entries contain important discussions of seemings, but I've put them in other parts of the book because I take their primary aim to be something else. These other important discussions include

\footnotetext{
${ }^{38}$ Weisberg (ms) extends this complaint to a variety of other rules, including Jeffrey conditionalization. See Pryor (S\&J, secs 7-8) for further discussion.
} 
Bergmann's section 1, Brogaard's section 3, Tooley's sections 2-4, Huemer's section 1, and, of course, the first section of this introduction.

In chapter 2, Andrew Cullison focuses on the propositional content of seemings. He argues that at least some seemings have Russellian propositions as contents. Roughly, a proposition is Russellian if it contains an object or property as a constituent. Whereas a Fregean might hold that the meaning of a name (e.g., 'Superman') is some associated description (e.g., the guy who flies around in blue spandex), Russellianism would hold that the object itself (Superman) is the meaning of the name ('Superman'). Cullison rejects a number of recent arguments in favour of Fregeanism about the content of perceptual seemings on the grounds that those arguments fail to distinguish between seemings and sensations. One upshot is that philosophers of mind have something to gain by paying attention to recent developments in the epistemological literature on seemings.

In chapter 3, Earl Conee's primary objective is to defend the Evidence-Taking account of seemings (assuming that seemings do exist) and its epistemological implications. Conee's motivation for the account pays careful attention to when it is correct to say that "it seems to me that so-and-so". Once we think of seemings as inclinations to believe of something that it counts in favor of $\mathrm{P}$, Conee maintains that we can be disabused of two extreme views: seemings never provide justification and seemings always provide justification. Suppose we are inclined to take $M$ as evidence for $P$. If it turns out that $M$ really is evidence for $\mathrm{P}$, then one component of the seeming, $\mathrm{M}$, justifies $\mathrm{P}$. For example, Conee holds that when $\mathrm{M}$ is an ordinary visual sensation, $\mathrm{M}$ is evidence for $\mathrm{P}$. In such a case, seemings provide justification; but they don't always do so. When $\mathrm{M}$ is evidentially irrelevant to $\mathrm{P}$, as it would be if $\mathrm{M}$ is my desire for $\mathrm{P}$, the seeming doesn't provide justification for P. One thing that emerges from Conee's discussion is that he endorses the distinction between seemings and sensations, and he holds that sensations, not seemings, are what do the primary justificatory work.

\subsection{Foundations of dogmatism}

The essays in Part II defend elements of dogmatism that are widely endorsed even among non-dogmatists. In chapter 4, Jessica Brown argues for Immediacy about Intuition: we have immediate, or non-inferential, justification to believe the contents of at least some of our intuitions. The standard way of arguing for this claim assumes that both perceptual experiences and intuitions are a form of seeming (see, e.g., Chudnoff 2011). Brown's arguments are less controversial because she does not assume that intuitions have any particular ontology. This neutrality allows her arguments to have much broader appeal than those directed at defending a very specific dogmatist thesis about intuition. Before discussing the motivation she finds successful, she considers whether regress arguments and the avoidance of scepticism can provide suitable motivations. She argues that they do not, and, contra popular opinion, she argues that, without supplementation, they fail to motivate even Immediacy about Perception, the claim that we at least sometimes have noninferential justification for the contents of our perceptual experiences. When she turns to her positive argument, she contends that Immediacy about Intuition provides the best explanation of our intuitions in Gettier Cases. Brown's examination of Gettier cases is an important contribution not only to the epistemology of intuition, but also the epistemology of philosophical method. 
In chapter 5, Jim Pryor defends dogmatism against the Bayesian objections, and he provides a comprehensive examination of the assumptions involved in such arguments. As he thinks of them, they target not merely dogmatism, but a far more modest and widely endorsed thesis he calls "credulism". Say that a potential underminer for $P$ is a proposition $\mathrm{U}$ such that justification for $\mathrm{U}$ would undermine a subject's justification for P. Credulism holds that there is at least one U, such that one's justification for P does not (even partially) consist in antecedent justification for U. Dogmatism is a very strong version of credulism. It holds that one's seeming-based justification does not consist in antecedent justification for any proposition, yet sceptical hypotheses are potential underminers for one's seemingbased justification that, say, one has hands. Credulism is compatible with the claim that justification (whether inferential or non-inferential) consists in antecedent justification for lots of propositions. It holds only that there is at least one U for P such that one's justification for $\mathrm{P}$ does not consist in antecedent justification for $\mathrm{U}$.

Pryor argues that, if we reject credulism, we must take one of two alternatives. The first continues to count all intuitive cases of undermining as genuine cases of undermining. The problem with this position, when combined with anti-credulism, is that it is committed to a suspicious regress of justification. The second denies that every intuitive case of undermining is a genuine case of undermining. In other words, to reject credulism-to hold that justification for $\mathrm{P}$ at least partially consists in antecedent justification for every potential underminer for $\mathrm{P}$-one must hold either (i) that justification requires never ending gobs of antecedent justification or (ii) that one limit the number of potential underminers in a counterintuitive way. Given that neither option is particularly appealing, we have reason to think that the Bayesian objection to dogmatism goes wrong somewhere. Much of Pryor's essay is then devoted to identifying precisely where it goes wrong.

\subsection{Seemings and internalism}

Part III concerns whether dogmatism or phenomenal conservatism, if true, provides a way of salvaging what we can call access internalism (AI). In its most generic form AI holds: S is justified in believing $\mathrm{P}$ only if $\mathrm{S}$ is aware of a justification contributor for believing $\mathrm{P}$, where a justification contributor is something that contributes to the justification of believing P. This sort of internalism, as such, imposes no constraints on which kinds of things can count as justification contributors. As far as AI is concerned, seemings, beliefs, and reliable processes could all be among the things that count as justification contributors. AI simply demands that the subject be aware of at least some of the things - whatever they are - that contribute to the justification of believing P. Proponents of AI include BonJour (1985) and Fumerton (1995).

Perhaps the most powerful objection to AI is Michael Bergmann's (2006, chs. 1, 2) socalled dilemma for internalism. In chapter 4, Matthias Steup rejects phenomenal conservatism but argues that seemings can nevertheless be used to resolve the dilemma. In chapter 5, Bergmann argues that seemings do not provide the resources to resolve his dilemma, and he specifically criticizes the proposals proffered by Steup (S\&J) and Rogers and Matheson (2011). Their disagreement over the alleged resolution of the dilemma reflects an even deeper disagreement over what is required to avoid the Subject's Perspective Objection (SPO).

The canonical presentation of the SPO is BonJour's (1985) Norman examples. Suppose a belief that P just pops into Norman's head. This belief isn't based on any other mental 
state, P doesn't seem true to Norman, and Norman has no relevant evidence concerning P's truth or whether the belief was formed in a reliable or otherwise appropriate way. In short, although Norman has no defeaters, there's nothing that supports P from Norman's perspective. There is wide agreement that Norman's belief that $\mathrm{P}$ is not justified, and this intuition remains even if we add that the belief was caused by some reliable, clairvoyant ability that Norman doesn't realize he has. Let us describe the problem with Norman's belief by saying that it is an accident from Norman's perspective that $P$ is true. To avoid the SPO, a theory of justification must prevent a subject from being justified in believing $\mathrm{P}$ whenever it would be an accident from the subject's perspective that $\mathrm{P}$ is true.

In the above Norman case, there is wide agreement that Norman's belief that $\mathrm{P}$ isn't justified; however, there is considerably less agreement concerning what is required to prevent it from being an accident from Norman's perspective that $\mathrm{P}$ is true. Comesaña (2010) holds that, as long as Norman has evidence that P is true (perhaps P seems true), then, from Norman's perspective, it is not an accident that $\mathrm{P}$ is true. As I understand them, Bergmann, Steup, and Huemer (S\&J, sec 2) all have the intuition that merely having evidence that $\mathrm{P}$ is not sufficient to prevent $\mathrm{P}$ from being an accident from the subject's perspective. I have the same intuition, albeit one that is weaker than the intuition I have regarding the Norman case from the previous paragraph.

What else might be required to prevent $P$ from being an accident from the subject's perspective? Steup provides one way of trying to make good on the following basic suggestion: Necessarily, (i) if $\mathrm{S}$ has evidence $\mathrm{E}$ for $\mathrm{P}$ and (ii) evidence E1 that E reliably indicates $\mathrm{P}$, then $\mathrm{P}$ is not an accident from $\mathrm{S}$ 's perspective. On the other hand, both Bergmann (S\&J, sec 3.3) and Huemer (S\&J, sec 2) deny that having E and E1 is, by itself, enough to prevent $\mathrm{P}$ from being an accident from the subject's perspective. ${ }^{39}$ They ultimately conclude that the intuitions behind the SPO demand too much and should be rejected altogether. ${ }^{40}$

\subsection{The significance of seemings within specific domains}

Part IV of the volume examines the significance that seemings have for specific domains. In chapter 8, Robert Audi's main goal is to identify what, if any, psychological and normative roles seemings play. Particular attention is paid to the domains of perception, intuition, memory, and testimony. He argues that, with the possible exception of intuitive ones (secs. 5.1-2), seemings fail to play any fundamental normative role ( $\sec 3$ ). On the other hand, seemings have such significant bearing on which beliefs we actually form, they may be ineliminable features of a "full-scale theory of rationality" ( $\sec 3$ ). Even here, though, Audi warns against overestimating the importance of seemings. Consider, for example, a rather ordinary case of testimony in which a person relates to us a rather long string of events. We very well may end up believing each part of the story. Yet it's

\footnotetext{
${ }^{39}$ Huemer (S\&J, sec 6.3) also claims that the details of Steup's position commit him to a vicious regress: having $\mathrm{E}$ and $\mathrm{E} 1$ is not enough, because one would also need, E2, evidence that $\mathrm{E} 1$ is reliable... and so on. Although Steup could be clearer on this point, he is not subject to any vicious regress. He's essentially a coherentist who thinks that seemings provide justification when supplemented by a certain kind of coherent belief structure that affirms the reliability of the seemings upon which the subject relies. Steup's sec 8 is relevant here, especially the connection he draws between his view and Sosa's (nt 24).

${ }^{40}$ My own view is that the SPO can motivate an important version of AI, but one importantly different than Steup's. My 2012 essentially uses the SPO to defend an AI about inferential justification. In future work, I plan to generalize the argument of that paper to defend a completely general version of AI.
} 
doubtful that each part of the story seems true. A more natural description is that we get "so wrapped up in [the] story...that the information provided simply flows into our belief system" (sec 2). If Audi is correct that many such testimonial beliefs are not based on seemings, then he may expose an important limitation of phenomenal conservatism: it cannot account for the justification of many of our testimonial beliefs.

In chapter 9, Michael DePaul considers the significance of seemings for the epistemology of disagreement, and he essentially objects to Feldman's (2007) dictum that evidence of evidence is evidence. Consider two subjects S1 and S2; it is not assumed that $\mathrm{S} 1$ and $\mathrm{S} 2$ are distinct. Also consider some arbitrary proposition $\mathrm{P}$ and some condition $\mathrm{C}$. The following thesis can be considered a formal presentation of Feldman's dictum:

Agent-Neutrality (AN)

Necessarily, for any S1, S2, P, and C, if S1's satisfying condition C would confer prima facie justification for $\mathrm{S} 1$ to believe $\mathrm{P}$, then $\mathrm{S} 2$ 's knowing that $\mathrm{S} 1$ satisfies $\mathrm{C}$ would confer equal prima facie justification for S2 to believe $P$.

The denial of AN is referred to as Agent Centeredness (AC). Suppose your seeming that $\mathrm{P}$ prima facie justifies you in believing $\mathrm{T}$ to degree .9 . If I know about your seeming, given $\mathrm{AN}$, this knowledge of your seeming prima facie justifies me in believing $\mathrm{T}$ to .9 .

If $\mathrm{AN}$ is false, i.e. if $\mathrm{AC}$ is true, then my knowledge of your seeming may provide me with some lower degree of prima facie justification for believing $\mathrm{P}$ or no prima facie justification at all. In such a case, S1 and S2 might reasonably disagree even though they recognize each other as peers and they have fully disclosed their evidence. To see this, suppose S1's total evidence is E+SEEMING, where SEEMING is S's seeming that $\mathrm{T}$ is true. S2's total evidence, on the other hand, is E+KNOWLEDGE, where KNOWLEDGE is S2's knowledge of S1's seeming. Given AC, E+SEEMING might provide ultima facie justification for $\mathrm{P}$ when $\mathrm{E}+\mathrm{KNOWLEDGE} \mathrm{provides} \mathrm{ultima} \mathrm{justification} \mathrm{for} \mathrm{believing} \sim \mathrm{P}$. This result would obtain because we are assuming that $\mathrm{AC}$ and that SEEMING provides better justification for $\mathrm{P}$ than does KNOWLEDGE.

DePaul shows that those sympathetic with the conjunction of dogmatism and AC have reason to be optimistic concerning the possibility of reasonable disagreements, even when the subjects recognize each other as epistemic peers and have fully disclosed their evidence. $^{41}$

\subsection{Dealing with cognitive penetration}

The three chapters in Part V try to find principled restrictions which allow dogmatism to avoid worries arising from cognitive penetration, especially the Tainted Source Objection (see sec 3.2 above).

In chapter 10, Matthew McGrath divides seemings into two categories: those that are quasi-inferred and those that aren't. Quasi-inferred seemings have "inference-like" dependence on either another seeming or a belief. Receptive seemings, those that aren't quasi-inferred, always provide foundational justification for their contents. Quasi-inferred seemings, on the other hand, at best provide derivative justification for their contents. In effect, a quasi-inferred seeming that $P$ derivatively justifies its content $P$ just in case the "basis" of the quasi-inferred seeming also justifies P. Consider the Wishful Willy case. McGrath holds that Willy's seeming that $(\mathrm{G})$ the object is gold is quasi-inferred from his

\footnotetext{
${ }^{41}$ The truth of AC might also enervate the Bayesian objections insofar as they rely on the proxy assumption.
} 
seeming that (Y) the object is yellowish. Since Y does not evidentially support G, Willy's seeming that $\mathrm{G}$ fails to justify, even derivatively, Willy's belief in $\mathrm{G}$.

In chapter 11, Peter Markie explores the Knowledge How Proposal, i.e. that seemings justify only if they are the products of knowledge how. According to this proposal, Wishful Willy isn't justified in believing that the object is gold because Willy doesn't know how to use visual phenomenology to identify gold nuggets.

With respect to perception, knowledge how boils down to a special kind of disposition. With respect to the a priori, knowledge how boils down to sufficient concept possession. Although some of the details are left for another occasion, Markie argues that the early returns on the proposal merit further investment.

In chapter 12, Berit Brogaard contends that the key to restricting dogmatism is a principle she calls "Content Grounding". This principle has two conditions which are individually necessary and jointly sufficient for a seeming to be content-grounded. The first requires seemings to be reliably correlated with the content of a perceptual, introspective, or memory-related experience. The second is reliabilist in character: S's seeming that $\mathrm{P}$ is content-grounded only if $\mathrm{S}$ 's seeming that $\mathrm{P}$ reliably indicates $\mathrm{P}$. Brogaard then defends what she calls "Sensible Dogmatism," that a seeming that $\mathrm{P}$ provides prima facie justification for P iff the seeming is content-grounded. At first glance, this proposal doesn't cover intellectual seemings because those seemings aren't reliably correlated with perceptual, introspective, or memorial experiences. On Brogaard's view, however, intellectual seemings spring from semantic memory; what we ordinarily call "a priori justification" is merely a special case of memorial justification.

\subsection{Phenomenal conservatism}

The three entries in part VI focus on endorsing or rejecting phenomenal conservatism. In chapter 13, William Lycan provides a novel way of motivating and defending the view. In the early stages of the paper, Lycan compares his earlier Principle of Credulity with Huemer's phenomenal conservatism and modifies his Principle of Credulity so that it is simply a version of phenomenal conservatism. Lycan's position is, however, no mere echo of Huemer's. Lycan provides entirely different motivations than does Huemer:

phenomenal conservatism resolves some problems in his explanationist coherentism, and Mother Nature would design us to rely on seemings. Furthermore, Lycan's version is considerably more modest than Huemer's (or mine for that matter) for two reasons. First, Lycan stresses that "the justification furnished by the Principle of Credulity is minute, the faintest edge, infinitesimal if you like" ( $\sec 7$ ), whereas Huemer and I both allow that very strong seemings may provide rather high degrees of justification. Second, and perhaps relatedly, Lycan holds that the justification provided by seemings is defeated more easily than Huemer or I intend. Suppose you are comparing two theories, T1 and T2, and that T1 strongly seems true to you and T2 strongly seems false to you. As it turns out, T2 is marginally simpler than T1. Huemer and I would want to leave it open that you could still have greater justification for T1 than T2. Lycan, on the other hand, says that any theoretical advantage of T2, no matter how small, will defeat the seeming-based justification you have for $\mathrm{T} 1$.

In chapter 14, Michael Tooley launches a wide-ranging attack on Huemer's version of

phenomenal conservatism. The three most important lines of attack, perhaps, are as follows. First, Tooley argues that Huemer's Experience View makes seemings unacceptably opaque or mysterious, and so he replaces it with the Evidence-Taking View. Second, he argues 
that PC is problematic because it allows seemings to justify even if (i) they are caused by other seemings, and even if (ii) they occur in the absence of any qualia or experience. Third, he argues that his own direct acquaintance approach is superior to phenomenal conservatism.

In chapter 15, Michael Huemer replies to several of the entries in this volume and focuses his attention on those by Brogaard, Conee, Markie, McGrath, and Steup. The three issues that receive the most attention are the nature of seemings, cognitive penetration, and the alleged superiority of PC over rival views proposed in the volume. The discussion of seemings is, I think, particularly helpful, and his replies confirm that phenomenal conservatism is a resilient view that deserves attention in spite of the problems it faces. ${ }^{42}$

\section{References}

Bealer, George. 2000. “A Theory of the A priori." Pacific Philosophical Quarterly 81, 130.

Bealer, George and P.F. Strawson. 1992. “The Incoherence of Empiricism.” Proceedings of the Aristotelian Society 66, 99-143.

Bergmann, Michael. 2006. Justification without Awareness. Oxford: Oxford University Press.

BonJour, Laurence. 1985. The Structure of Empirical Knowledge. Cambridge: Harvard University Press.

Chudnoff, Eli. 2011. "The Nature of Intuitive Justification." Philosophical Studies 153, 313-33.

Comesaña, Juan. 2010. "Reliabilist Evidentialism.” Noûs 44, 571-600.

Cullison, Andrew. 2010. "What Are Seemings?” Ratio 23(3), 260-74.

DePaul, Michael. 2009. "Phenomenal Conservatism and Self-Defeat." Philosophy and Phenomenological Research 78, 205-12.

DePoe, J.M. 2011. "Defeating the Self-Defeat Argument for Phenomenal Conservatism." Philosophical Studies 152, 347-59.

Feldman, Richard. 2007. 'Reasonable Religious Disagreements.' In Philosophers without Gods, edited by Antony, Louise, 194-214. Oxford: Oxford University Press.

Fumerton, Richard. 1995. Metaepistemology and Skepticism. Lanham, MD: Rowman \& Littlefield.

Goldman, Alvin. 2009. "Internalism, Externalism, and the Architecture of Justification." The Journal of Philosophy 106, 309-38.

Hasan, Ali. 2011. "Phenomenal Conservatism, Classical Foundationalism, and Internalist

Justification." Philosophical Studies, doi: 10.1007/s11098-011-9751-0

Huemer, Michael. 1999. "The Problem of Memory Knowledge." Pacific Philosophical Quarterly, 80, 346-57. . 2001. Skepticism and the Veil of Perception. Lanham: Rowman \& Littlefield

Publishers, Inc.

\footnotetext{
${ }^{42}$ Thanks to Robert Audi, Marinus Ferreira, Matthew Flanagan, Paul Silva, Jr, and the audience at the University of Otago for helpful discussion on earlier drafts of the paper. Thanks especially to Michael Huemer for helpfully commenting on multiple drafts and to James Pryor for detailed discussion when the deadline was nigh. Finally, thanks to the University of Auckland's Faculty Research Development Fund for supporting this project.
} 
. 2006. "Phenomenal Conservatism and the Internalist Intuition." American Philosophical Quarterly 43: 147-58.

. 2007. "Compassionate Phenomenal Conservatism." Philosophy and Phenomenological Research 74, 30-55.

. 2009. "Apology of a Modest Intuitionist." Philosophy and Phenomenological

Research 78: 222-36.

. 2011a. "Phenomenal Conservatism and Self-Defeat: A Reply to DePoe."

Philosophical Studies 156, 1-13.

. 2011b. "Epistemological Egoism and Agent-Centered Norms." In Dougherty, Trent

(ed.). Evidentialism and its Discontents. Oxford: Oxford University Press, 17-33

Jackson, Alexander. 2011. "Appearances, Rationality and Justified Belief." Philosophy and Phenomenological Research 82, 564-93.

Jackson, Frank. 1977. Perception: A Representative Theory. Cambridge: Cambridge University Press.

Jehle, David and Brian Weatherson. Manuscript. "Dogmatism and Intuitionistic Probability."

Kung, Peter. 2010. "On Having No Reason: Dogmatism and Bayesian Confirmation.” Synthese 177, 1-17.

Lycan, William G. 1988. Judgement and Justification. Cambridge: Cambridge University Press.

Lyons, Jack. 2009. Perception and Basic Beliefs. New York: Oxford University Press. . 2011. "Circularity, Reliability and the Cognitive Penetrability of Perception." Philosophical Issues 21: 289-311.

Markie, Peter. 2005. "The Mystery of Perceptual Justification." Philosophical Studies 126, 347-73.

Plantinga, Alvin. 1993. Warrant and Proper Function. Oxford: Oxford University Press. Pollock, John L. and Joseph Cruz. 1999. Contemporary Theories of Knowledge. $2^{\text {nd }}$ ed.

Lanham: Rowman \& Littlefield.

Pryor, James. 2000. "The Skeptic and the Dogmatist." Noûs 34(4), 517-49. . 2004. "What's Wrong with Moore's Argument?" Philosophical Issues 14: 349-77.

. Forthcoming. "When Warrant Transmits." In Wittgenstein, Epistemology and Mind: Themes from the Philosophy of Crispin Wright, edited by Annelisa Coliva. Oxford: Oxford University Press. . Manuscript. "Uncertainty and Undermining."

Rogers, Jason and Jonathan Matheson. 2011. "Bergmann's Dilemma: Exit Strategies for Internalists." Philosophical Studies, 152(1), 55-80.

Schiffer, Stephen. 2004. "Skepticism and the Vagaries of Justified Belief." Philosophical Studies 119, 161-84.

Siegel, Susanna. 2005. "Which Properties are Represented in Perception?" in Perceptual Experience, edited by Tamar Szabó Gendler and John Hawthorne, 481-503. Oxford: Oxford University Press. . 2012. "Cognitive Penetrability and Perceptual Justification." Noûs 46: 201-222. . Forthcoming. "The Epistemic Impact of the Etiology of Experience." Philosophical Studies.

Skene, Matthew. Forthcoming. "Seemings and the Possibility of Epistemic Justification", Philosophical Studies. dx.doi.org/10.1007/s11098-011-9830-2 
Sosa, Ernest. 1998. “Minimal Intuition.” In Rethinking Intuition, edited by Michael DePaul and William Ramsey, 257-70. Lanham, MD: Rowman \& Littlefield. . 2007. A Virtue Epistemology, volume 1. Oxford: Oxford University Press.

Swinburne, Richard. 2001. Epistemic Justification. Oxford: Oxford University Press.

Tolhurst, William. 1998. "Seemings.” American Philosophical Quarterly 35, 293-302.

Tucker, Chris. 2010a. "Why Open-Minded People Should Endorse Dogmatism."

Philosophical Perspectives 24, 529-45. . 2010b. "When Transmission Fails." Philosophical Review 119, 497-529. . 2011. "Phenomenal Conservatism and Evidentialism in Religious Epistemology."

In Evidence and Religious Belief, edited by Clark, Kelly James and Raymond

VanArragon. Oxford: Oxford University Press. . 2012. "Movin' On Up: Higher-Level Requirements and Inferential Justification."

Philosophical Studies 157(4), 323-40. . Manuscript. "If Dogmatists Have a Problem with Cognitive Penetration, You Do Too."

Weatherson, Brian. 2007. "The Bayesian and the Dogmatist." Proceedings of the Aristotelian Society 107: 169-85.

Wedgwood, Ralph. Forthcoming. "A Priori Bootstrapping." In Casullo, Albert and Joshua Thurow (eds.). The A Priori in Philosophy. Oxford: Oxford University Press. Weisberg, Jonathan. Manuscript. "Updating, Undermining, and Independence." . 2009. "Commutativity or Holism? A Dilemma for Conditionalizers." British Journal for Philosophy of Science 60, 793-812.

White, Roger. 2006. "Problems for Dogmatism." Philosophical Studies 31, 525-57.

Williamson, Timothy. 2007. The Philosophy of Philosophy. Oxford: Blackwell.

Wright, Crispin. 2007. "Perils of Dogmatism." In Themes from G. E. Moore: New Essays

in Epistemology and Ethics, edited by Susana Nuccetelli and Gary Seay, 25-48. Oxford: Oxford University Press. 